\title{
Epidemiological, Clinical and Therapeutic Aspects of Spinal Pathology in Military People in a Country at War
}

\author{
Mamadou Salia Diarra1,2, Mohamed El Hassimi Cissé1,2, Izoudine B. Koumaré1, \\ Oumar Diallo ${ }^{3}$, Drissa Kanikomo ${ }^{4}$
}

${ }^{1}$ Military Neurosurgery Unit, Infirmerie Hôpital de Bamako (IHB), Bamako, Mali

${ }^{2}$ Neurosurgery Department, Hôpital Mère-Enfant-Bamako, USTT-B (Université des Sciences, des Techniques et des Technologies de Bamako), Bamako, Mali

${ }^{3}$ Neurosurgery Department, Hôpital du Mali, USTT-B, Bamako, Mali

${ }^{4}$ Neurosurgery Department, Hôpital Gabriel Touré, USTT-B, Bamako, Mali

Email: madoucha@hotmail.com

How to cite this paper: Diarra, M.S., E Hassimi Cissé, M., Koumaré, I.B., Diallo, O. and Kanikomo, D. (2022) Epidemiological, Clinical and Therapeutic Aspects of Spinal Pathology in Military People in a Country at War. Open Journal of Modern Neurosurgery, 12, 39-46.

https://doi.org/10.4236/ojmn.2022.121004

Received: November 14, 2021

Accepted: January 14, 2022

Published: January 17, 2022

Copyright $\odot 2022$ by author(s) and Scientific Research Publishing Inc. This work is licensed under the Creative Commons Attribution International License (CC BY 4.0).

http://creativecommons.org/licenses/by/4.0/

\begin{abstract}
Introduction: Lumbar and sciatic pain are frequent motives of disability in military people in Mali. As spine surgery isn't recognized enough, our study aims to analyze etiologies, epidemiology, clinical features and surgical standards in order to improve troop abilities. Methodology: Our descriptive and retrospective study has included 31 operated military patients who underwent medical or surgical procedures between 2010 and 2018 in the Military Neurology/Neurosurgery Unit and Mère-Enfant Hospital Neurosurgery department. Results: Among 553 seen in consultation, fifty percent were between 30 and 50 years old. Main motive was sciatic pain (65.5\%). Seventy eight percent of our patients were field militaires and sub-officers, and $83.2 \%$ were males. All of them have benefited a CT scan or MRI with medical treatment in rheumatology or neurology. Thirty-one patients underwent spine surgery and were included in the study, so 6\% (mean age: 43.52 years, $90.3 \%$ males). Lumbar spine surgery represented $54.8 \%$ of cases with lumbar canal stenosis in $64.5 \%$ of cases. It appeared that spondylolisthésis with isthmic fracture was frequent (12.9\%), and traumatic cervical spine fractures were dominant in 2012. Instrumented arthrodesis was performed for $41.9 \%$ of patients, lumbar discectomy for $32.3 \%$ and laminectomies for $22.6 \%$. Degenerative etiology was found in $77.4 \%$ of cases and we've noticed a good outcome in $93.5 \%$ of operated cases. Conclusion: Spinal pathology in military people in Mali is in relation with training, weight carrying and transport conditions on tough terrain. Traumatic traffic injuries are the most common even in war time.
\end{abstract}




\section{Keywords}

Military, Spine, Spondylolisthesis, Mali

\section{Introduction}

Lumbar pain and sciatic are known as frequent motives for consultation [1] [2] and disability among military people [3]. Tough work [4], weight carrying, micro-traumatisms and increased life expectancy, enable traumatic and degenerative vertebral lesions such as spondylolisthesis [5] [6] [7] [8] [9]. Our country is actually in an assymetric war against terrorism and various medical structures treat military patients. Spine surgery is developing progressively but remains still unrecognized in our country.

No study has been done before, neither to describe and assess spinal disease and its impact on military abilities, nor to present results of spine surgery.

\section{Methodology}

Our work was a retrospective, descriptive and multicentric study. It aimed to describe epidemiology, clinical features, etiologies, and neurosurgical standards for spinal pathologies of military people.

Thirty one military operated patients, who underwent medical procedures between 2010 and 2018 in the Military Neurology/Neurosurgery Unit (IHB) or Mère-Enfant Hospital Neurosurgery Unit, were chosen among 553 medically followed ones. Incomplete medical files has not been retained. Clinical information was collected from medical consulting and surgical files.

Patients has been followed before surgery and surgical indication has been asked in the event of treatment failure or neurological worsening. Systematic pre-operative visit has been done. Post-operative follow-up has permitted to classify results in "good" (pain improvement, neurological improvement, mobility recovery), and "bad" (neurological worsening, no changes in pain or palsy). Military ranks, epidemiological and clinical data, post-operative outcome has been analyzed with SPSS.

\section{Results}

Basically, of the 553 patients, non-commissionned officers and rankers represented $78.4 \%$; 50.2\% were between 30 and 50 years old. We've found $83.2 \%$ of men. Sciatic pain was the main reason for consultation in 65.5 percent of cases. The etiology was labeled degenerative in $93.4 \%$ of cases and traumatic in $6.8 \%$ of cases. All of them have received medical treatment and have also benefited from imaging tests such as computed tomography (CT scan), myelography or Magnetic resonance imaging (MRI).

We centered our study on 31 operated patients: $90.3 \%$ were male and the average age was 43.52 years. Seventy decimal three percent $(70.3 \%)$ of the operated 
patients were between the ages of 30 and 70 and degenerative etiologies were more frequent after 50 years old (16/19 then $84 \%)$.

The surgery involved the lumbar spine in 26 cases (83.9\%). Discal herniations were the most common with 17 cases (54.8\%), 50\% before 40 years old, excluded in 3 cases with lumbar canal stenosis associated in $16.1 \%$ (Table 1). Fractureluxations of the cervical spine has been noticed in 5 patients (16.1\%). They were dominant among traumatic injuries and more frequent in 2012 than other years. Spondylolisthesis by isthmic lysis was noticed in 4 cases, or $12.9 \%$ and 2 parachutists among them.

Surgery was scheduled in $81.5 \%$ of cases. Instrumented arthrodesis represented $41.9 \%$, discectomies $32.3 \%$ and laminectomies $25.8 \%$ (Table 2).

The etiology of the lesions was mainly degenerative (77.4\%) including degenerative spondylolisthesis (Figure 1). Patients also reported the notion of low back pain or a notion of traumas or accidents during transport in 16 cases (51.6\%). Three patients were parachutists.

Among 3 explosions reported, one traumatic lumbar injury with burst fracture from a mine blast (Figure 2) was observed.

The post operative outcome was good in $93.5 \%$ of cases and we noticed one death.

Twenty operated patients received functional and motor rehabilitation (64\%) after surgery.

\section{Discussion}

The incidence of low back pain is estimated to be between $4.1 \%$ and $6.3 \%$ among

Table 1. Distribution of patients according to the per-operative diagnosis.

\begin{tabular}{lcc}
\hline Diagnostic & Staff & Percentage \\
\hline Discal herniation & 12 & $38.7 \%$ \\
Discal herniation with Lumbar canal stenosis & 5 & $16.1 \%$ \\
Fracture-luxation (cervical spine) & 5 & $16.1 \%$ \\
Spondylolisthésis/isthmic Lisis & 4 & $12.9 \%$ \\
Lumbar canal stenosis & 3 & $9.7 \%$ \\
Lumbar canal stenosis and Cervico-Arthrosic myelopathy & 2 & $6.5 \%$ \\
TOTAL & 31 & $100 \%$ \\
\hline
\end{tabular}

Table 2. Distribution of patients by operative technique.

\begin{tabular}{lcc}
\hline Technique & Staff & Percentage \\
\hline Lumbar laminectomy & 7 & 22.6 \\
Discectomy & 10 & 32.3 \\
Cervical Laminectomy & 1 & 3.2 \\
cervical or lumbar arthrodesis & 13 & 41.9 \\
TOTAL & 31 & 100 \\
\hline
\end{tabular}




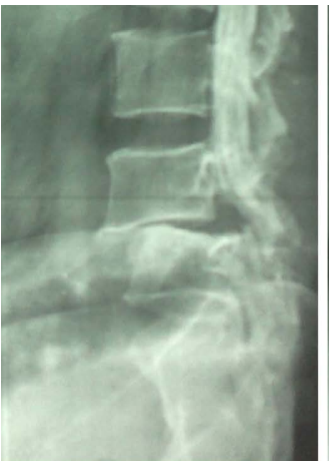

(a)

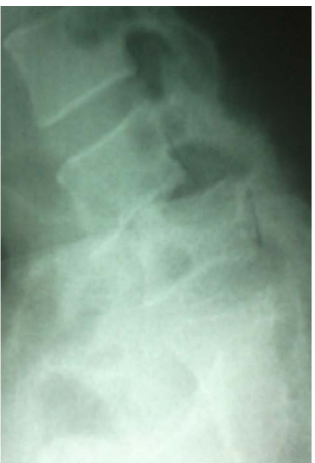

(b)

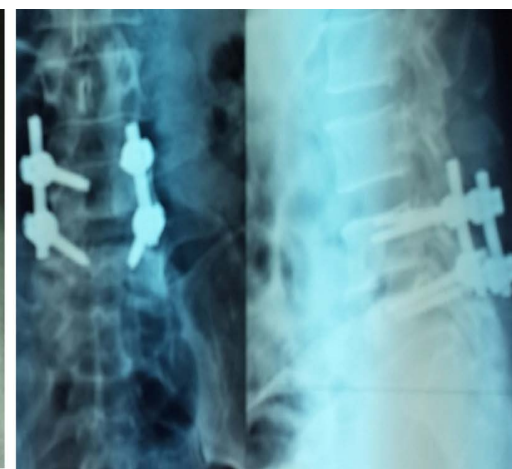

(c)

Figure 1. ((a), (b)) Colonel Z.N., retired, repeated missions with patrols, root claudication, sphincter disorders, sciatic pain, grade 3 spondylolisthesis with instability. (c) Postoperative control $\mathrm{X}$ ray with reduced listhesis, spectacular clinical recovery.

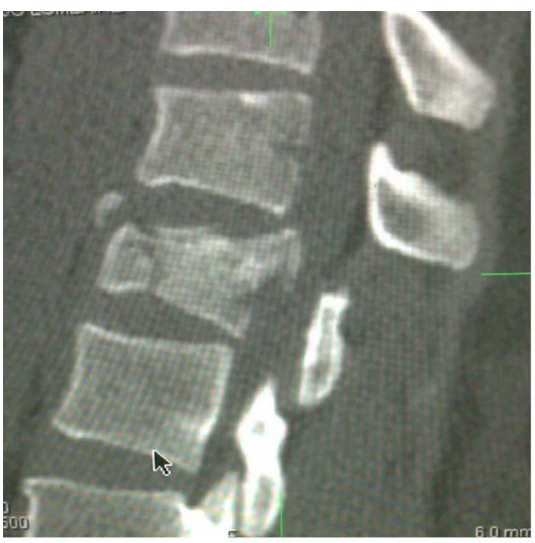

(a)

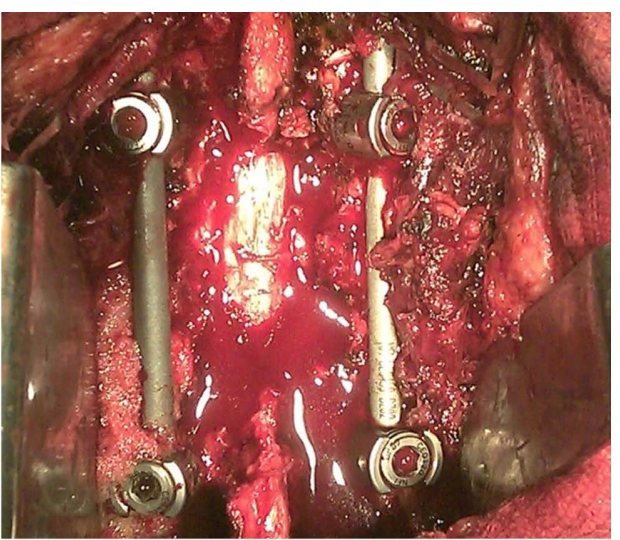

(b)

Figure 2. (a) Corporal M.C, Military. Passenger of a vehicle on patrol hit by an IED (improvised explosive device), sanitary evacuation from battlefield, L3 burst fracture, Spinal cord section syndrome; (b) Per-operative view.

military men in the US, and between $7.5 \%$ and $9.9 \%$ among women [10]. In Mali, there is no centralized data and our study is the first specific to the spinal pathology in the military. A surgical indication was evoked for $30 \%$ of patients but only thirty one were operated (or 6\%) during the period.

The management cost is poorly estimated but compulsory Health Insurance (since 2011-2012) has facilitated the management of spinal surgery in the military, but they are often carried out in civilian hospitals for cooperation reasons or lack of infrastructure in the various barracks.

In Mali, Keita [11], reported an average age of 52.62 years old in civilian people operated for degenerative spinal pathology, which is 7 years older than military in our study. The lesions in our study were in relation with the age $(\mathrm{p}=$ 0.015).

Nevertheless, the age and sex of our patients were comparable to those found by Moussavou-Imounga [12] about spondylolisthesis, but reported a higher frequency of spondylolisthesis in civilian women (55\%). Mama et al. [13], reported $48 \%$ of military between the ages of 30 - 39 years, suffering from spinal degener- 
ative pathology, including a majority of men (94\%).

Sciatic and low back pains were also found by Gbelle [14] in $70.46 \%$ of cases, as well as in several military studies during deployments in Iraq and Afghanistan [15] [16]. Soldiers of combat units (army, gendarmerie, paratroopers) would therefore be more exposed [15] [17].

In terms of rank, Mama et al. [13] reported $80 \%$ of officers and the lumbar spine as the most affected (91.41\%), which is consistent with our study.

The frequency of spondylolisthesis by isthmic lysis in men is described by other authors [5] [6] [7] [8] [9], and could be explained by the sex ratio of men in the army but also by the mechanical constraints related to the wearing of loads, training and the field trade.

Like reported in other studies [13] [14], traumatic or degenerative etiologies we've found was mainly related to military training, difficult conditions or accidents during transport or patrols ( $4^{\star} 4$ and trucks, vehicle falls, road conditions). The scarcity of purely traumatic etiologies (mine explosions, bombings) in our study could be explained by their management in other centers.

In imaging, lumbar lesions were more frequent in Gbelle's study [14] with $73.2 \%$ of cases, with $55 \%$ of degenerative and $37 \%$ traumatic injuries. These data includes all explored patients and are lower than those found in our study.

The frequency of cervical spine injuries in 2012 could be explained by the increase in patrols during the anti-jihadist campaign (vehicle rollovers).

The frequency of spondylolisthesis by isthmic lysis (12\%) in military in our study was superior to the general population (3\% according to Belfi [18]. This is also described by other authors for parachutists [6] [7] (8.8\% according to [19]), or high-level athletes (6.6\% according to [20]. These injuries could be either a direct consequence or a worsening of pre-existing injury (stress fracture, congenital malformation or hyper-solicitation), responsible of incapacity in some army corps [9] [20] [21] [22] [23]. Therefore, like in other countries [21], we do think that research and screening for disabling injuries [4] such as spondylolisthesis or isthmic lysis, might be the subject of a radiological assessment during recruitment, because they are not as systematic as other lesions can be (knee injuries). In France, this condition is referenced in the Ministerial Instruction 2100 [8], chapter II, section A-Rachis, article 105 "Bilateral spondylolysis". Surgical treatment concerns about $10 \%$ of patients [21] in cases of isthmic lysis.

Commonly described contributing or aggravating factors are hyperlordosis [24], common in African Black, female [25] and repetitive trauma.

Spondylolisthesis among civilian women represented 55\% according to Moussavou-Imounga [12] and could then be explained by biomechanical factors (lordosis++) and working conditions (carrying loads, lumbar bending to work or to sweep, do laundry or cooking).

Mama et al. [13] showed a link between the higher prevalence of lumbar degenerative disease after 50 years (6.3\%), mobility (53\%), duration of active service over 5 years, location of service (northern patrols, mobile units). He also 
found $16 \%$ of explored patients were operated against $6 \%$ in our study (the percentage was calculated for all patients who underwent imaging tests).

Degenerative lesions were treated in programmed surgery, instabilities and trauma necessitated a stabilization by an arthrodesis. An in-depth analysis of injuries by types of military personnel is necessary in our study, for elite corps such as parachutists (4 cases), who appears to be more exposed to mechanical constraints and load carrying [2] [3].

Spine surgery is unknown and has a bad reputation, because of a very important psychological and social impact (beliefs of sexual weaknesses, attributable to back pain). But a good outcome was also found by Keita [11] with $91.5 \%$ of cases. Nevertheless, the patients may often require workstation changes [13].

According to Ricordeau [26], applications for disability pensions are also frequent from patients with spinal pathologies. Consideration should be given for revising the design of troop transport vehicles and the use of orthopaedic means (lumbar corsets) [10].

Our study limits are the lack of complete data about all the military operated for spinal pathologies, because of their management in different sanitary and civilian structures.

\section{Conclusions}

Even in a country in war, degenerative lesions of the lumbar spine and isthmic lysis are dominant and affect active military personnel. Traumatic degenerative lesions are directly attributable to transport and field conditions. Number of traumatic injuries increased during 2012 at the beginning of war.

Surgical treatment enables good outcome, but instructors and assessment boards must consider these features for recruitment, engaging, training and transport conditions, in order to safeguard the soldier's fitness [19]. The reinsertion of military with spine injuries is an important operational and socio-economic issue.

\section{Conflicts of Interest}

The authors declare no conflicts of interest regarding the publication of this paper.

\section{References}

[1] Houzou, P., Oniankitan, O., Kakpovi, K., et al. (2013) Profil des affections rhumatismales chez 13517 patients ouest africains. La Tunisie Médicale, 91, 16-20.

[2] Gourmelena, J., Chastanga, J.F., Ozgulera, A., et al. (2007) Fréquence des lombalgies dans la population française de 30 à 64 ans. Résultats issus de deux enquêtes nationales. Annales de Réadaptation et de Médecine Physique, 50, 633-639. https://doi.org/10.1016/j.annrmp.2007.05.008

[3] Couratte, Y., Haus-Cheymol, R., Lebleu, C., et al. (2007) Caractéristiques des arrêts de travail dans un régiment de l’armée de Terre. Médecine et Armées, 35, 411-415.

[4] Ndundu, J., Kota, L., Luviluka, J., et al. (2013) Prévalence de la lombalgie chronique 
dans une population de travailleurs d'une entreprise de manutention. Journal de Réadaptation Médicale, 33, 80-85. https://doi.org/10.1016/j.jrm.2013.07.002

[5] Jacquot, F. (2014) Spondylolyse et Spondylolisthésis isthmique chez l'adulte. Maîtrise Orthopédique, Paris.

[6] Kirkpatrick, A.W. (1991) Spondylolysis and Spondylolisthesis in Military Parachutists. Military Medicine, 156, 687-690. https://doi.org/10.1093/milmed/156.12.687

[7] Bar-Dayan, Y., Weisbort, M., Bar-Dayan, Y., Velan, G.J., Ravid, M., Hendel, D., et al. (2003) Degenerative Disease in Lumbar Spine of Military Parachuting Instructors. Journal of the Royal Army Medical Corps, 149, 260-264. https://doi.org/10.1136/jramc-149-04-03

[8] Instruction ministérielle $\mathrm{N}^{\circ}$ 2100/DEF/DCSSA/AST/AME du ler octobre 2003 relative à la détermination de l'aptitude médicale à servir.

[9] Gervaise, A., Naulet, P., Pernin, M., Darbois, H. and Girodeau, A. (2008) Intérêt de l'imagerie dans le diagnostic des fractures de fatigue du militaire. Médecine et Armées, 36, 353-358.

[10] Lechevalier, D. (2010) Incidence et prévention des lombalgies en milieu militaire. Une base pour des recommandations. Médecine et Armées, 38, 17-21.

[11] Keita, A. (2018) Traitement chirurgical du canal lombaire étroit dans le service de neurochirurgie du chu mère-enfant "le luxembourg": À propos de 145 cas. Université des Sciences, Techniques et Technologies de Bamako, Bamako.

[12] Moussavou-Imounga, L.J. (2021) Aspects épidémiologiques, cliniques et radiologiques des patients opérés pour spondylolisthésis au CHU-Mère Enfant "Le Luxembourg" de Bamako. Mémoire de des de radiodiagnostic et imagerie Médicale. Université des Sciences, Techniques et Technologies de Bamako, Bamako.

[13] Mama et al. (2019) Epidemiology of Degenerative Pathologies of the Rachis at the National Gendarmerie in Ivory Coast. Greener Journal of Epidemiology and Public Health, 7, 6-17.

[14] Gbelle, B. and Kouassi, P. (2014) Diagnostic tomodensitométrique de pathologies rachidiennes chez les agents des forces de l'ordre Militaires, Gendarmes et Policiers à HMA-Abidjan, Côte d'Ivoire. Thèses et Mémoires UFHB, Abidjan. https://inveniov1.uvci.edu.ci/record/6403/

[15] Nissen, L.R., Marott, J.L. and Gyntelberg, F. (2014) Deployment-Related Risk Factors of Low Back Pain: A Study among Danish Soldiers Deployed to Iraq. Military Medicine, 179, 451-458. https://doi.org/10.7205/MILMED-D-13-00317

[16] Monnier, A., Larsson, H., Djupsjöbacka, M., et al. (2015) Musculoskeletal Pain and Limitations in Work Ability in Swedish Marines: A Cross-Sectional Survey of Prevalence and Associated Factors. BMJ Open, 5, e007943. https://doi.org/10.1136/bmjopen-2015-007943

[17] Roy, T.C., Lopez, H.P. and Piva, S.R. (2013) Loads Worn by Soldiers Predict Episodes of Low Back Pain during Deployment to Afghanistan. Spine, 15, 1310-1317. https://doi.org/10.1097/BRS.0b013e31829265c4

[18] Belfi, L.M., Ortiz, A.O. and Katz, D.S. (2006) Computed Tomography Evaluation of Spondylysis and Spondylolisthesis in Asymptomatic Patients. Spine, 31, E907-E910. https://doi.org/10.1097/01.brs.0000245947.31473.0a

[19] Murray-Leslie, C.F., Lintott, D.J. and Wright, V. (1977) The Spine in Sport and Veteran Military Parachutists. Annals of the Rheumatic Diseases, 36, 332-342. https://doi.org/10.1136/ard.36.4.332

[20] Rossi, F. and Dragoni, S. (2001) The Prevalence of Spondylolysis and Spondylolis- 
thesis in Symptomatic Elite Athletes: Radiographic Findings. Radiography, 7, 37-42. https://doi.org/10.1053/radi.2000.0299

[21] Garetier, M., Chinellato, S., Barberot, C., Feuvrier, Y., Le Bivic, T. and Rousset, J. (2011) Spondylolisthésis par lyse isthmique: Revue de la littérature, évaluation radiologique et aptitude. Médecine et Armées, 40, 135-142.

[22] Wiltse, L.L., Newman, P.H. and Macnab, I. (1976) Classification of Spondylolysis and Spondylolisthesis. Clinical Orthopaedics and Related Research, 117, 23-29. https://doi.org/10.1097/00003086-197606000-00003

[23] Fredrickson, B.E., Baker, D., McHolick, W.J., Yuan, H.A. and Lubicky, J.P. (1984) The Natural History of Spondylolysis and Spondylolisthesis. The Journal of Bone \& Joint Surgery, 66, 699-707. https://doi.org/10.2106/00004623-198466050-00008

[24] Dietrich, M. and Kurowski, P. (1985) The Importance of Mechanical Factors in the Etiology of Spondylolysis. A Model Analysis of Loads and Stresses in Human Lumbar Spine. Spine, 10, 532-542. https://doi.org/10.1097/00007632-198507000-00007

[25] Blackburne, J.S. and Velikas, E.P. (1977) Spondylolisthesis in Children and Adolescents. The Journal of Bone and Joint Surgery. British Volume, 59, 490-494.

[26] Ricordeau, P. et al. (2001) Les causes médicales des pensions d'invalidité nouvellement attribuées en 1998. Données du Régime général de l'Assurance Maladie. CNAMTSEchelon National du Service Médical-Département Soins de Ville.

https://www.ameli.fr/fileadmin/user upload/documents/Causes medicales pension s invalidite.pdf 